\title{
Participation of locus coeruleus in breathing control in female rats
}

\author{
Débora de Carvalho a,b, Luis Gustavo A. Patrone ${ }^{a}$, Danuzia A. Marques ${ }^{\mathrm{a}}$, Mariane C. Vicente ${ }^{\mathrm{a}}$, \\ Raphael E. Szawka ${ }^{c}$, Janete A. Anselmo-Franci ${ }^{d}$, Kênia C. Bícego ${ }^{a}$, Luciane H. Gargaglioni ${ }^{\mathrm{a}, *}$ \\ a Department of Animal Morphology and Physiology, Sao Paulo State University - UNESP/FCAV, Jaboticabal, SP, Brazil \\ b Federal Institute of Education, Science and Technology - IFPA,Tucuruí, PA, Brazil \\ c Department of Physiology and Biophysics, Institute of Biological Sciences, Federal University of Minas Gerais - UFMG, Belo Horizonte, MG, Brazil \\ ' Department of Stomatology, Morphology and Physiology, FORP-University of Sao Paulo at Ribeirao Preto, SP, Brazil
}

\section{A R T I C L E I N F O}

\section{Keywords:}

A6 group

$\mathrm{CO}_{2}$

Estradiol

Noradrenaline

Breathing

\begin{abstract}
A B S T R A C T
Several evidences indicate that the locus coeruleus (LC) is involved in central chemoreception responding to $\mathrm{CO}_{2} / \mathrm{pH}$ and displaying a high percentage of chemosensitive neurons ( $>80 \%$ ). However, there are no studies about the LC-mediated hypercapnic ventilation performed in females. Therefore, we assessed the role of noradrenergic LC neurons in non-ovariectomized (NOVX), ovariectomized (OVX) and estradiol (E2)-treated ovariectomized (OVX + E2) rats in respiratory response to hypercapnia, using a 6-hydroxydopamine (6-OHDA) lesion model. A reduction in the number of tyrosine hydroxylase (TH) immunoreactive neurons $(51-90 \%$ in 3 animals of NOVX group, $20-42 \%$ of lesion in 5 animals of NOVX females, $61.3 \%$ for OVX and $62.6 \%$ for OVX + E2 group) was observed seven days after microinjection of 6-OHDA in the LC. The chemical lesion of the LC resulted in decreased respiratory frequency under normocapnic conditions in OVX and OVX + E2 group. Hypercapnia increased ventilation in all groups as consequence of increases in respiratory frequency (fR) and tidal volume $\left(\mathrm{V}_{\mathrm{T}}\right)$. Nevertheless, the hypercapnic ventilatory response was significantly decreased in 6-OHDANOVX $>50 \%$ rats compared with SHAM-NOVX group and with females that had $20-42 \%$ of LC lesion. In OVX and OVX + E2 lesioned groups, no difference in $\mathrm{CO}_{2}$ ventilatory response was observed when compared to SHAM-OVX and SHAM-OVX + E2 groups, respectively. Neither basal body temperature (Tb) nor Tb reduction in response to hypercapnia were affected by E2 treatment, ovariectomy or LC lesion. Thus, our data show that LC noradrenergic neurons seem to exert an excitatory role on the hypercapnic ventilatory response in female rats, as evidenced by the results in NOVX animals with LC lesioned more than 50\%; however, this modulation is not observed in OVX and OVX + E2 rats. In addition, LC noradrenergic neurons of OVX females seem to provide a tonic excitatory drive to maintain breathing frequency in normocapnia, and this response may not to be functionally influenced by E2.
\end{abstract}

\section{Introduction}

Locus coeruleus (LC) has the largest noradrenergic group in central nervous system (CNS), the A6 region (Moore and Bloom, 1979; Dahlström and Fuxe, 1964), and it has been associated with a number of physiological and behavioral functions including cardiovascular, respiratory control, sleep-wake cycle, feeding, thermoregulation, nociception, attention and learning (De Carvalho et al., 2010; De Souza Moreno et al., 2010; Biancardi et al., 2008; Almeida et al., 2004; Putnam et al., 2004; Oyamada et al., 1998; Aston-Jones et al., 1985; Hobson et al., 1975).

LC has been shown to exert an important excitatory role in the ventilatory response to hypercapnia (Silva et al., 2017; Patrone et al.,
2014; Taxini et al., 2013; De Carvalho et al., 2010; Biancardi et al., 2008). Indeed, some studies suggest that LC neurons act directly as $\mathrm{CO}_{2} / \mathrm{pH}$ chemosensors and that $80 \%$ of these neurons are chemosensitive responding to hypercapnia with increased firing rate (Filosa et al., 2002; Oyamada et al., 1998; Pineda and Aghajanian, 1997; Coates et al., 1993).

In addition to modulating physiological functions, LC is involved in several disorders, including panic disorder, post-traumatic stress and depression (Singewald and Philippu, 1998) which are prevalent in women (Andrade et al., 2006). This prevalence appears to be linked to hormonal and reproductive events (Rapkin et al., 2002). It is known that estrogen receptors alpha (ER $\alpha)$ and beta (ER $\beta)$ are expressed in noradrenergic neurons of the LC in female mice (Pendergast et al.,

\footnotetext{
* Corresponding author at: Via de acesso Paulo Donato Castellane s/n, 14870-000, Departamento de Morfologia e Fisiologia Animal, Faculdade de Ciências Agrárias e Veterinárias, Universidade Estadual Paulista Júlio de Mesquita Filho, Jaboticabal, SP, Brazil.

E-mail address: lucihel@fcav.unesp.br (L.H. Gargaglioni).
} 
2008) and that high levels of estradiol (E2) reduce the activity of LC neurons during normocapnia, suggesting an inhibitory role for E2 in this nucleus (De Carvalho et al., 2016).

Previous studies have shown that female rats need a continuous presence of E2 for the development of LC, since the absence of this modulation promotes a decrease in the volume and in the number of LC neurons (De Blas et al., 1990; Segovia et al., 1990; Guillamóm et al., 1988). Moreover, the activity of LC neurons is modulated by this hormone (Szawka et al., 2009) and E2 administration in ovariectomized rats (OVX) produces a dose-dependent elevation in tyrosine hydroxylase (TH) mRNA levels in LC (Serova et al., 2002).

As LC is an important nucleus in chemoreception in males and there are no studies about the LC-mediated hypercapnic ventilation performed in females, we investigated the role of LC in the respiratory response to $\mathrm{CO}_{2}$ in female rats. Our hypothesis is that $\mathrm{LC}$ noradrenergic neurons exert an excitatory control in the hypercapnic ventilatory response in females and E2 modulates this response. Therefore, we assessed the role of these neurons in non-ovariectomized (NOVX), ovariectomized (OVX) and E2-treated ovariectomized (OVX + E2) rats in the respiratory response to hypercapnia by using 6-hydroxydopamine (6-OHDA), a neurotoxin that destroys selectively catecholaminergic neurons in the brain.

\section{Methods}

\subsection{Animals}

Experiments were performed on unanesthetized adult female Wistar rats weighing 250-310 g. The animals had free access to water and food and were housed in controlled temperature room $\left(25 \pm 1{ }^{\circ} \mathrm{C}\right)$ with a 12:12 h light:dark cycle (lights on at 6:00 am). Estrous cycle regularity was assessed in females and only rats showing at least three consecutive regular 4-day cycles were subject to surgery and then to the ventilatory experiment. The study was conducted in compliance with the guidelines of the National Council for the Control of Animal Experimentation (CONCEA, MCT, Brazil) and with the approval of the local Animal Care and Use Committee (CEUA, FACV-UNESP Jaboticabal; \# 000222-09).

\subsection{Experimental design}

Fig. 1 shows a schematic diagram of experimental design. The selective chemical lesions of LC neurons were performed in female rats seven days before the ventilatory experiment. Rats were stereotaxically injected with 6-OHDA in the LC and after brain surgery some animals were submitted to ovariectomy. A week later, each animal was individually placed in a plexiglass chamber $(5 \mathrm{~L})$ and allowed to move freely while the chamber was flushed with humidified air. After approximately $30 \mathrm{~min}$ of adaptation, control ventilation was measured. Next, a hypercapnic gas mixture $\left(7 \% \mathrm{CO}_{2}\right.$ in air breathing) was flushed through the chamber for $45 \mathrm{~min}$ and Ve was measured at the end of $\mathrm{CO}_{2}$ exposure. Tb was continuously recorded throughout the experiment. All ventilatory experiments were conducted between 8:00 am and 13:00 pm.

\subsection{Anesthesia and post-surgical treatment}

All surgical procedures were performed under anesthesia with ketamine $(100 \mathrm{mg} / \mathrm{Kg}$, i.p.; Agener, SP, Brazil) and xylazine $(10 \mathrm{mg} / \mathrm{Kg}$, i.p.; Coopers, SP, Brazil), antibiotic protection $(10 \mathrm{mg} / \mathrm{kg}$, s.c.; Enrofloxacina, Flotril, Schering-Plough, SP, Brazil) and analgesic $(2.5 \mathrm{mg} / \mathrm{kg}$, s.c.; Flunixina meglumina, Banamine; Schering-Plough, SP, Brazil).

\subsection{Brain surgery}

For selective chemical lesions rats were fixed to a stereotaxic frame (David Kopf Instruments, Kent, England) and the coordinates to locate LC $(-3.1,-3.4$ and $-3.7 \mathrm{~mm}$ from lambda; $\pm 1.2 \mathrm{~mm}$ from midline; $-7.0 \mathrm{~mm}$ from the skull surface; incisive bar at $0 \mathrm{~mm}$; inclination of vertical stereotaxic bar at $15^{\circ}$ ) were based on the stereotaxic atlas for rats (Paxinos and Watson, 1998). Aiming to achieve the full extent of the LC (rostral, medial and caudal nucleus portions) 3 bilateral microinjections with a distance of $0.3 \mathrm{~mm}$ between each point were performed. The tip of a needle was inserted into LC for injection of 6-OHDA (Sigma Aldrich, St Louis, MO, USA) solution of $8 \mu \mathrm{g} / 1 \mu \mathrm{L}$ of vehicle as previously described (Biancardi et al., 2008). Sham rats were injected with vehicle ( $1 \mu \mathrm{g}$ ascorbic acid - Sigma Aldrich, St Louis, MO, USA- in $0.1 \mu \mathrm{L}$ of saline). At each point, it was microinjected $0.250 \mu \mathrm{L}$ (6-OHDA or vehicle) over $6 \mathrm{~min}$ each microinjection, totaling $0.750 \mu \mathrm{L}$ for each side of the LC.

\subsection{Ovariectomy and hormone treatment}

A group of animals was submitted to ovariectomy by midline laparotomy. Three consecutive days prior to the experiment the females were treated with vehicle (corn oil, OVX group; $0.2 \mathrm{~mL} / \mathrm{rat}$, s.c.) or with $17 \beta$-estradiol (OVX + E2 group; $10 \mu \mathrm{g} / 0.2 \mathrm{~mL} / \mathrm{rat}$, s.c., oestradiol cypionate; Pfizer, SP, Brazil; Szawka et al., 2009; De Carvalho et al., 2016) at 10:00 am On the fourth day, rats were tested in the ventilatory experiment.

\subsection{Datalogger implantation}

For body core temperature $(\mathrm{Tb})$ measurements, a temperature datalogger (SubCue, Calgary, AB, Canada) was implanted in the abdominal cavity through a midline laparotomy one day before experiments. The datalogger was programmed to acquire data at every $5 \mathrm{~min}$.

\subsection{Experimental groups}

In the present study, the term SHAM is referring to the animals that had ascorbic acid (vehicle) microinjected in the LC. Our animals were divided in seven groups: 1) non-ovariectomized females that vehicle was microinjected in the LC (SHAM-NOVX, $\mathrm{n}=5$ ); 2) non-ovariectomized females that 6-OHDA was microinjected in the LC and promoted a lesion of noradrenergic neurons larger than 50\% (6-OHDANOVX $>50 \%, \mathrm{n}=3$ ); 3) non-ovariectomized females that 6-OHDA was microinjected in the LC and promoted a lesion of noradrenergic neurons between 20 and 42\% (6-OHDA-NOVX 20-42\%, $n=5)$; 4) ovariectomized females that vehicle was microinjected in the LC and

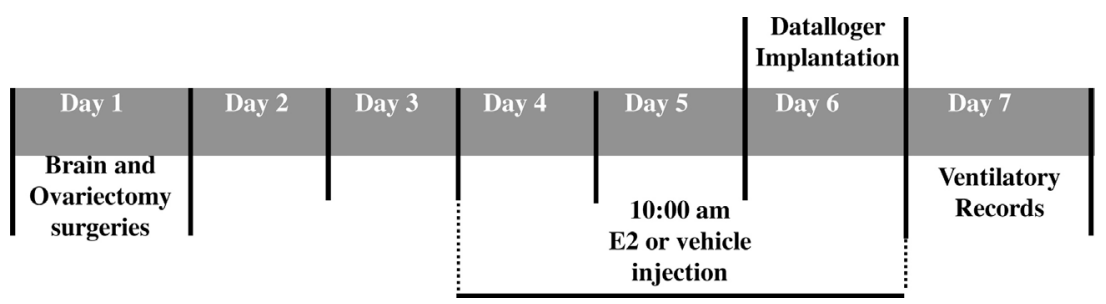

Fig. 1. Schematic diagram of experimental design. 


\section{A}

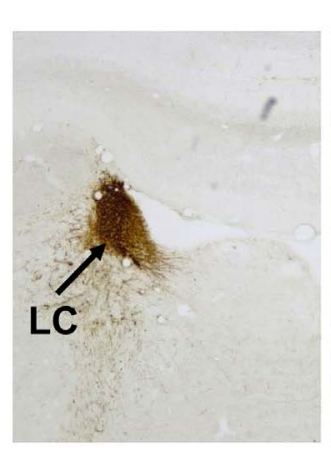

SHAM

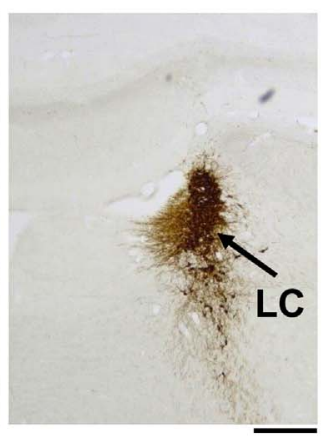

C

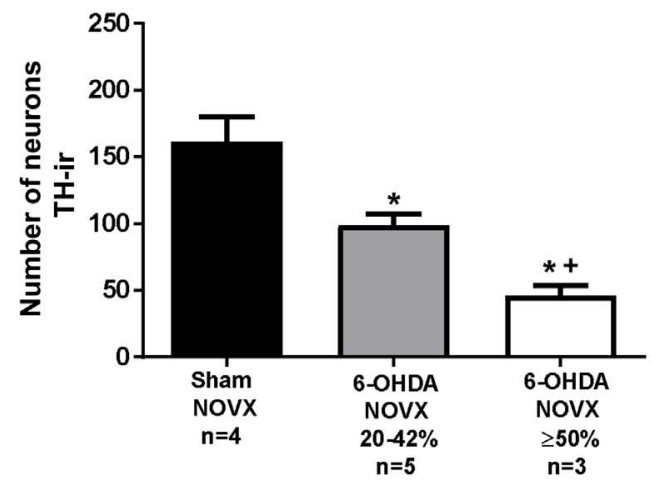

E

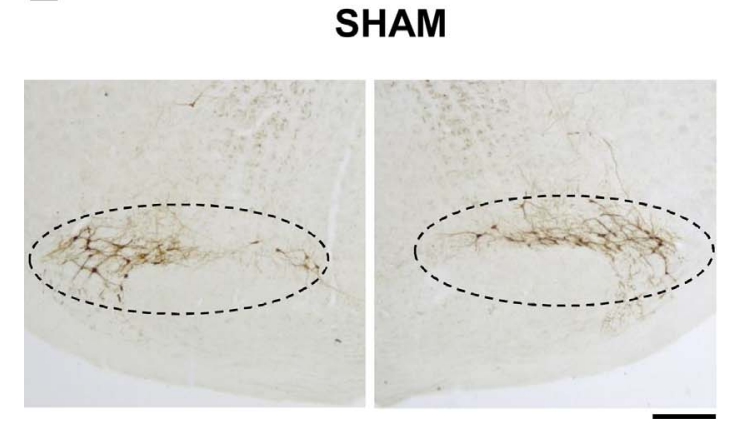

B

\section{6-OHDA}

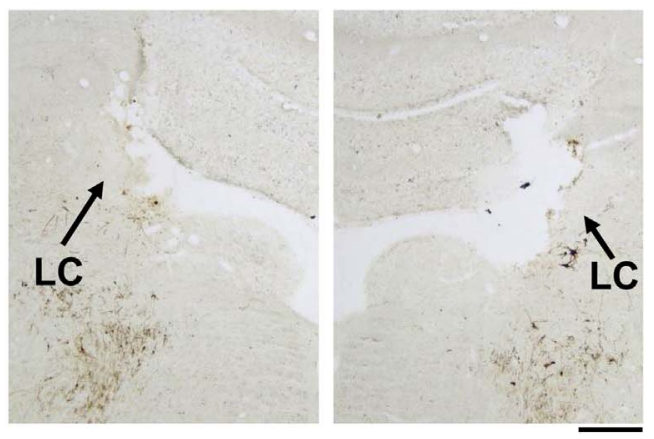

D

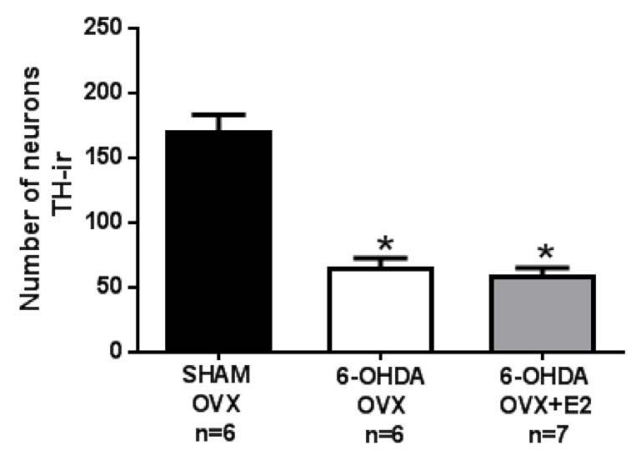

F

\section{6-OHDA}
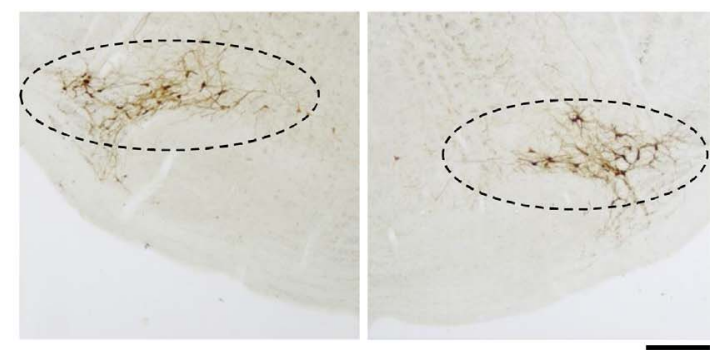

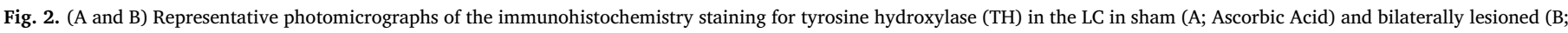

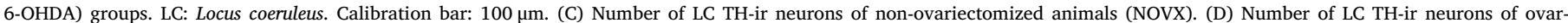

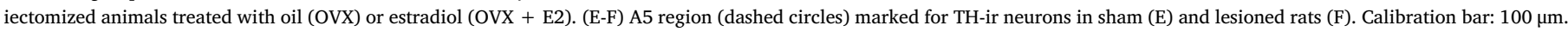

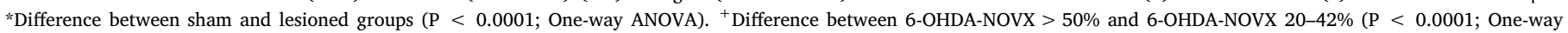
ANOVA).

received corn oil subcutaneously (SHAM-OVX, $n=6$ ); 5) ovariectomized females that 6-OHDA was microinjected in the LC and received corn oil subcutaneously (6-OHDA-OVX, $\mathrm{n}=7$ ); 6) ovariectomized females that vehicle was microinjected in the LC and received E2 subcutaneously (SHAM-OVX + E2, $\mathrm{n}=7$ ); 7) ovariectomized females that 6-OHDA was microinjected in the LC and received E2 subcutaneously (6-OHDA-OVX + E2, $\mathrm{n}=7$ ).

\subsection{Determination of pulmonary ventilation}

Measurements of pulmonary ventilation $\left(\mathrm{V}_{\mathrm{E}}\right)$ were performed using the whole body plethysmograph method (Bartlett and Tenney, 1970) as previously described (for details see De Carvalho et al., 2010; Biancardi et al., 2008). Freely moving rats were kept in a 5-L chamber ventilated with humidified room air or with a mixture containing $7 \% \mathrm{CO}_{2}$ in air $\left(7 \% \mathrm{CO}_{2}, 21 \% \mathrm{CO}_{2}\right.$ and $\mathrm{N}_{2}$ balance - White Martins, Sertãozinho, SP, Brazil). The animal chamber operates with inflow of humidified gas, and the flow rate was maintained in $0.8-1.0 \mathrm{~L} / \mathrm{min}$ by a flowmeter (model 822-13-OV1-PV2-V4, Sierra Instruments, Monterey, CA, USA). The air temperature in the chamber was monitored by datalogger (SubCue, Calgary, AB, Canada) and the chamber was constantly humidified and humidity was settled as $100 \%$. The results were analysed 

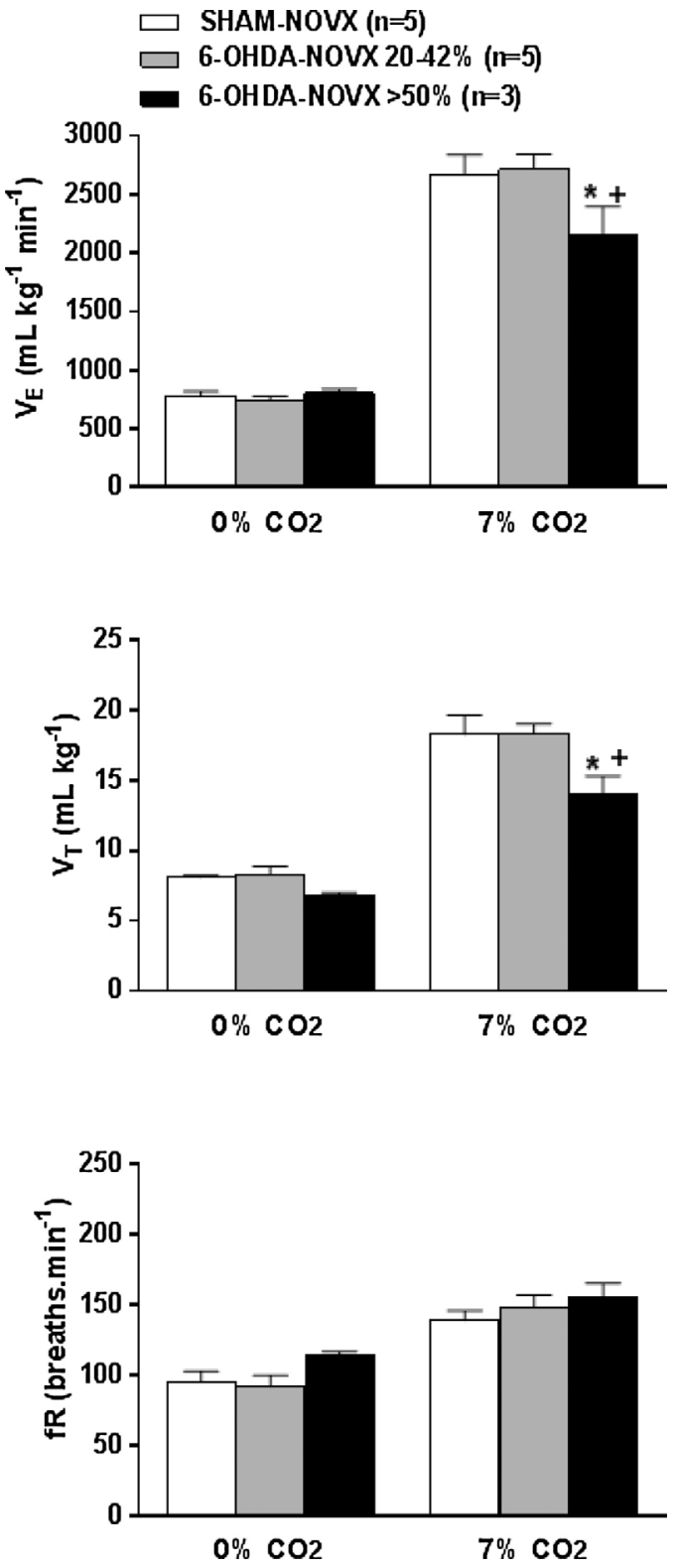

Fig. 3. Ventilation $\left(V_{E}\right)$, tidal volume $\left(V_{T}\right)$ and respiratory frequency $(f R)$ in sham nonovariectomized females (SHAM-NOVX), non-ovariectomized females that 6-OHDA promoted a LC lesion larger than 50\% (6-OHDA-NOVX > 50\%) and non-ovariectomized females that 6-OHDA promoted a LC lesion between 20 and 42\% (6-OHDA-NOVX $20-42 \%)$ exposed to normocapnia and hypercapnia $\left(7 \% \mathrm{CO}_{2}\right)$. *Difference between SHAM-NOVX and 6-OHDA-NOVX $>50 \%$. ${ }^{+}$Difference between 6-OHDA-NOVX $>50 \%$ and 6-OHDA-NOVX $20-42 \%$.

with the data-analysis software Acqknowledge (v3.8.1 data acquisition system, Biopac Systems Inc., Santa Barbara, CA, USA).

\subsection{Hormone assay}

After ventilatory experiments, OVX and OVX + E2 rats were anesthetized with ketamine and xylazine and a blood sample of approximately $1 \mathrm{~mL}$ was collected from the heart into heparinized syringes. Plasma was separated by centrifugation at $3000 \mathrm{rpm}$ for $20 \mathrm{~min}$ at $4^{\circ} \mathrm{C}$ and stored at $-20^{\circ} \mathrm{C}$ for posterior analyses of $\mathrm{E} 2$ levels by radioimmunoassay (RIA). E2 plasma concentrations were determined by double-antibody RIA with MAIA kits provided by Biochem Immunosystem (Bologna, Italy). The lower limits of detection for E2 were $5.0 \mathrm{pg} / \mathrm{mL}$ and the intra-assay coefficient of variation was $4.3 \%$.

\subsection{Assessment of 6-OHDA chemical lesion effectiveness and placement}

Rats under deep ketamine and xylazine anesthesia were transcardially perfused with PBS followed by $4 \%$ paraformaldehyde in $0.1 \mathrm{~m}$ phosphate buffer. Frontal sections of $25 \mu \mathrm{m}$ were cut through the LC region in a cryostat (Microm, Model HM500 OM, Germany). To verify the correct placement and effectiveness of the chemical lesions, tyrosine hydroxylase (TH) immunoreactivity was assessed as a marker of catecholaminergic neurons (Xu et al., 2003). To this purpose, the sections were incubated for $48 \mathrm{~h}$ with monoclonal mouse anti-TH antibody (Sigma, MO, USA) at 1:10000 followed by $2 \mathrm{~h}$ incubation with a biotinylated rabbit polyclonal anti-mouse (Dako, Denmark) at 1:1000. The biotinylated antibody was complexed with avidin DH-biotinylated horseradish peroxidase (PK-4001, Vector Laboratories, Burlingame, CA, USA), and the complex was developed by addition of the peroxidase substrate 3,3'-diaminobenzidine tetrahydrochloride (DAB) according to manufacturer's instructions (Sigma, MO, USA). Sections were mounted on gelatin-coated glass slides. Photomicrographs were captured using AxioVision software (from Carl Zeiss, Munich, Germany). To estimate the ablation of TH-ir neurons caused by 6-OHDA, we counted the number of TH-immunoreactive (ir) neurons bilaterally in $25-\mu \mathrm{m} \mathrm{sec-}$ tions (9.16-10.32 mm from bregma). Analyses were performed using a computerized image analysis system Image J (US National Institutes of Health).

\subsection{Data processing and analysis}

The results are reported as means \pm SEM. Ventilatory and temperature data were analysed using Two-way ANOVA followed by the Bonferroni post-hoc test. The reduction of LC noradrenergic neurons was determined by One-way ANOVA. Statistical analyses were performed using GraphPad Prism (La Jolla, CA, USA). Values of $\mathrm{P}<0.05$ were considered to be significant. In the graphs, the differences between normocapnia and hypercapnia are not represented, only differences between groups (sham and 6-OHDA) with statistical significance.

\section{Results}

\subsection{Assessment of 6-OHDA chemical lesion effectiveness and placement}

The immunohistochemistry for TH shows the effectiveness of chemical lesions of the LC with 6-OHDA (Fig. 2). The LC of SHAM groups was intact and typically appeared as a compact cluster of intensely stained cells (Fig. 2A). Successful bilateral 6-OHDA- lesions of the LC were revealed mostly by the decrease of TH-positive cells (Fig. 2B). THir neurons were quantified after 6-OHDA microinjection in NOVX, OVX and OVX + E2 groups. In NOVX animals, 3 females presented a reduction of TH-ir neurons larger than 50\% compared to SHAM-NOVX group, whereas in other 5 females, 6-OHDA decreased TH-ir LC neurons from $20 \%$ to $42 \%$ (Fig. 2C; P < 0.0001; One-way ANOVA). In OVX and $\mathrm{OVX}+\mathrm{E} 2$ groups, chemical lesion caused a reduction of TH-ir neurons higher than 50\%. Injections of 6-OHDA into the LC reduce TH-ir cells in the LC of OVX (61.3\% of reduction, P $<0.0001$; One-way ANOVA) and OVX $+\mathrm{E} 2$ rats $(62.6 \%$ of reduction, $\mathrm{P}<0.0001$; One-way ANOVA) with no difference between OVX and OVX + E2 rats (Fig. 2D). We can observe that lesion was selective to the LC since the noradrenergic population of neurons in the A5 region, remained preserved after the microinjections of 6-OHDA (Fig. 2E-F).

\subsection{Estrous cycle stages, pulmonary ventilation and body temperature of non-ovariectomized females}

In SHAM-NOVX group 3 rats were in diestrus and 2 in estrus. After LC lesions, all rats remained in diestrus (data not shown).

Fig. 3 presents the $\mathrm{V}_{\mathrm{E}}, \mathrm{V}_{\mathrm{T}}$ and $\mathrm{fR}$ values of SHAM (Ascorbic acid) and LC- lesioned (6-OHDA-NOVX > 50\% and 6-OHDA-NOVX 20-42\%) 

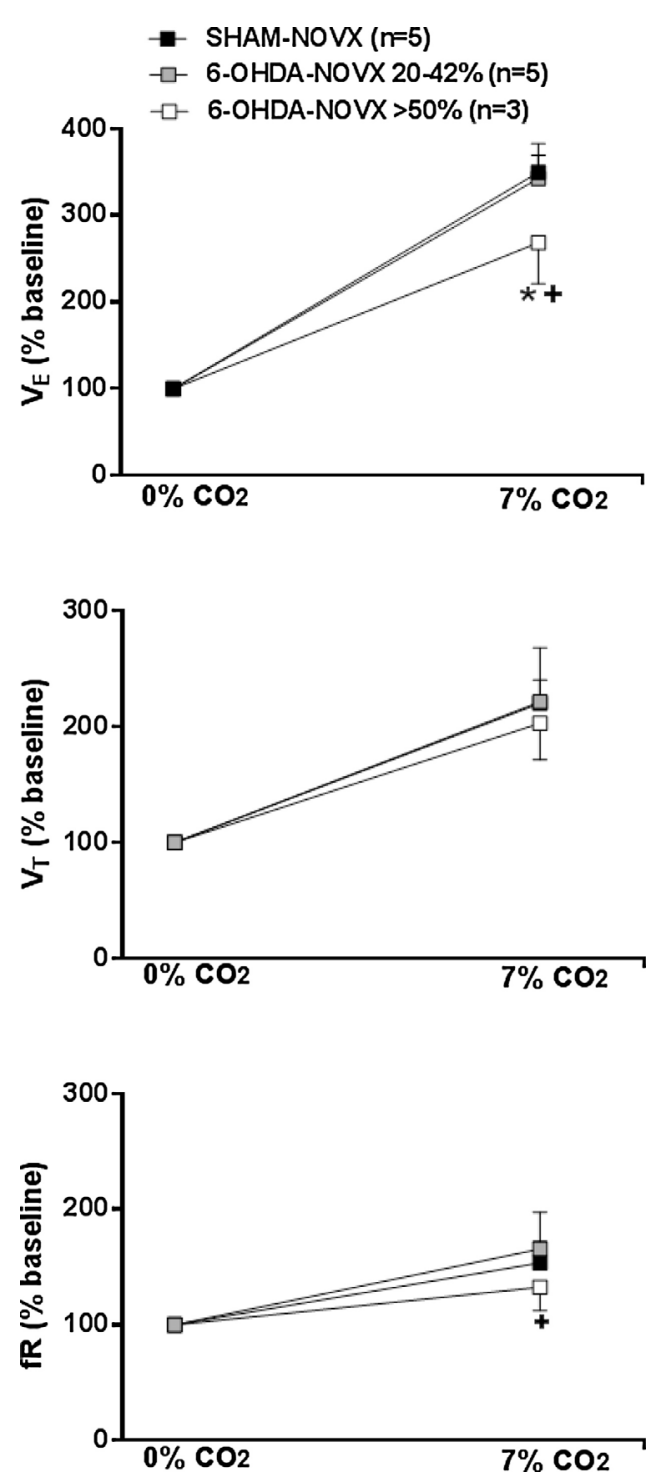

Fig. 4. The relative changes in ventilation $\left(V_{E}\right)$, tidal volume $\left(V_{T}\right)$ and respiratory frequency ( $f R$ ) in sham non-ovariectomized females (SHAM-NOVX), non-ovariectomized females that 6-OHDA promoted a LC lesion larger than 50\% (6-OHDA-NOVX > 50\%) and non-ovariectomized females that 6-OHDA promoted a LC lesion between 20 and $42 \%$ (6-OHDA-NOVX 20-42\%). Data are expressed relative (\%) to levels before $\mathrm{CO}_{2}$ administration as means \pm SEM. *Difference between SHAM-NOVX and 6-OHDANOVX $>50 \% .{ }^{+}$Difference between 6-OHDA-NOVX $>50 \%$ and 6-OHDA-NOVX $20-42 \%$.

rats during normocapnia and hypercapnia $\left(7 \% \mathrm{CO}_{2}\right)$. Under normocapnic conditions, the lesion did not change the values of $\mathrm{V}_{\mathrm{E}}, \mathrm{V}_{\mathrm{T}}$ and $\mathrm{fR}$. Hypercapnia caused an increase in $\mathrm{V}_{\mathrm{E}}(\mathrm{P}<0.0001$; Two-way ANOVA) due to an increase in both $\mathrm{V}_{\mathrm{T}}(\mathrm{P}<0.0001$; Two-way ANOVA) and $\mathrm{fR}$ $(\mathrm{P}<0.0001$; Two-way ANOVA) in all groups. The hypercapnic ventilatory response was significantly decreased in 6-OHDA-NOVX $>50 \%$ rats compared with SHAM-NOVX (P $<0.05$; Two-way ANOVA) and 6OHDA-NOVX 20-42\% (P < 0.05, Two-way ANOVA). During $\mathrm{CO}_{2}$ exposure, $\mathrm{V}_{\mathrm{T}}$ was lower in 6-OHDA-NOVX $>50 \%$ rats compared to SHAM and 6-OHDA-NOVX 20-42\% (P $<0.05$ for SHAM-NOVX and $\mathrm{P}<0.01$ for 6-OHDA-NOVX 20-42\%, Two-way ANOVA).

To emphasize the effect of 6-OHDA lesion on the sensitivity to $\mathrm{CO}_{2}$, we expressed the hypercapnic responses as percent changes from baseline (Fig. 4). The $\mathrm{CO}_{2}$ ventilatory response of 6-OHDA-NOVX > $50 \%$ animals was lower compared to SHAM and 6-OHDA-NOVX $20-42 \%$ ( $\mathrm{P}<0.01$ for both groups, Two-way ANOVA), and at least compared to 6-OHDA-NOVX $20-42 \%$, this effect was due to a reduced

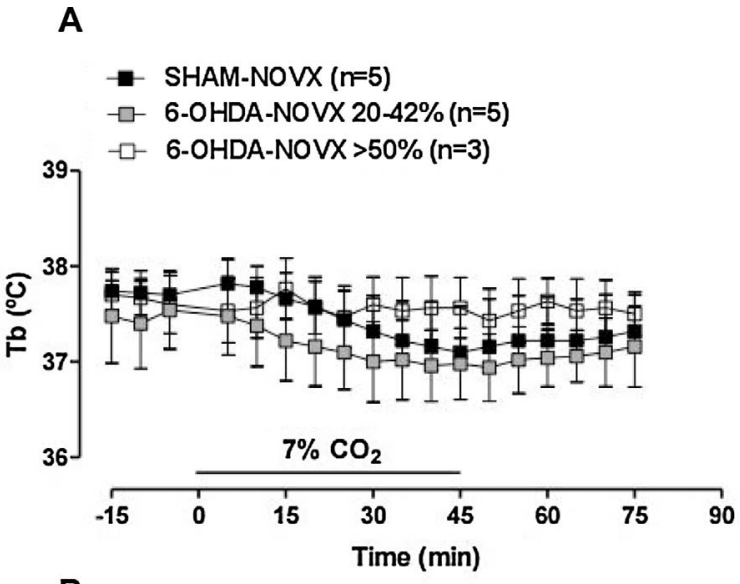

B

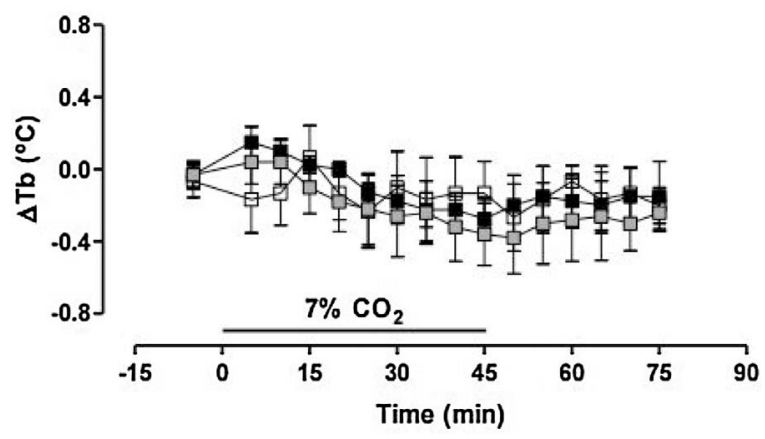

Fig. 5. (A) Body core temperature (Tb) in sham non-ovariectomized females (SHAMNOVX), non-ovariectomized females that 6-OHDA promoted a LC lesion larger than $50 \%$ (6-OHDA-NOVX $>50 \%$ ) and non-ovariectomized females that 6-OHDA promoted a LC lesion between 20 and 42\% (6-OHDA-NOVX 20-42\%) during normocapnia and hypercapnia $\left(7 \% \mathrm{CO}_{2}\right)$. (B) Variation in body core temperature (Tb) in SHAM-NOVX, 6OHDA-NOVX > 50\%, and 6-OHDA-NOVX 20-42\%.

\section{fR $(\mathrm{P}<0.05$, Two-way ANOVA).}

Fig. 5A presents the effects of the LC lesion on Tb in NOVX rats during normocapnia and hypercapnia. Hypercapnia reduced $\mathrm{Tb}$ in all groups $(\mathrm{P}<0.05$; Two-way ANOVA) and ablation of LC neurons had any effect on $\mathrm{Tb}$. The graphic of variation in $\mathrm{Tb}$ (Fig. $5 \mathrm{~B}$ ) shows that a fall in $\mathrm{Tb}$ caused by hypercapnia was similar in all groups $(\mathrm{P}<0.0001$; Two-way ANOVA).

\subsection{Plasma hormone concentrations, pulmonary ventilation and body temperature of ovariectomized females}

Table 1 shows plasma E2 concentrations in SHAM and 6-OHDA groups after ovariectomy (OVX) and ovariectomy with E2 replacement (OVX + E2). The OVX + E2 group showed higher plasma E2 levels than OVX rats $(\mathrm{P}<0.001)$ in both SHAM and 6-OHDA animals.

During room air conditions, the lesion did not change the values of $\mathrm{V}_{\mathrm{E}}$ and $\mathrm{V}_{\mathrm{T}}$, but reduced $\mathrm{fR}$ in both $\mathrm{OVX}$ and $\mathrm{OVX}+\mathrm{E} 2$ group $\left(\mathrm{P}<0.05\right.$; Two-way ANOVA) (Fig. 6). Hypercapnia enhanced $\mathrm{V}_{\mathrm{E}}$ in all groups $\left(\mathrm{P}<0.0001\right.$; Two-way ANOVA) due to an increase in both $\mathrm{V}_{\mathrm{T}}$

Table 1

Plasma estradiol levels in 6-OHDA and sham groups after ovariectomy (OVX) and ovariectomy with E2 replacement (OVX + E2).

\begin{tabular}{lll}
\hline & ESTRADIOL $(\mathrm{pg} / \mathrm{mL})$ & \\
\hline & SHAM & $6-O H D A$ \\
OVX & $72.4 \pm 8.9(\mathrm{n}=6)$ & $64.7 \pm 2.9(\mathrm{n}=7)$ \\
OVX + E2 & $123.7 \pm 8.9^{*}(\mathrm{n}=7)$ & $112.7 \pm 8.8^{*}(\mathrm{n}=7)$ \\
\hline
\end{tabular}

Results are reported as mean \pm SEM. 

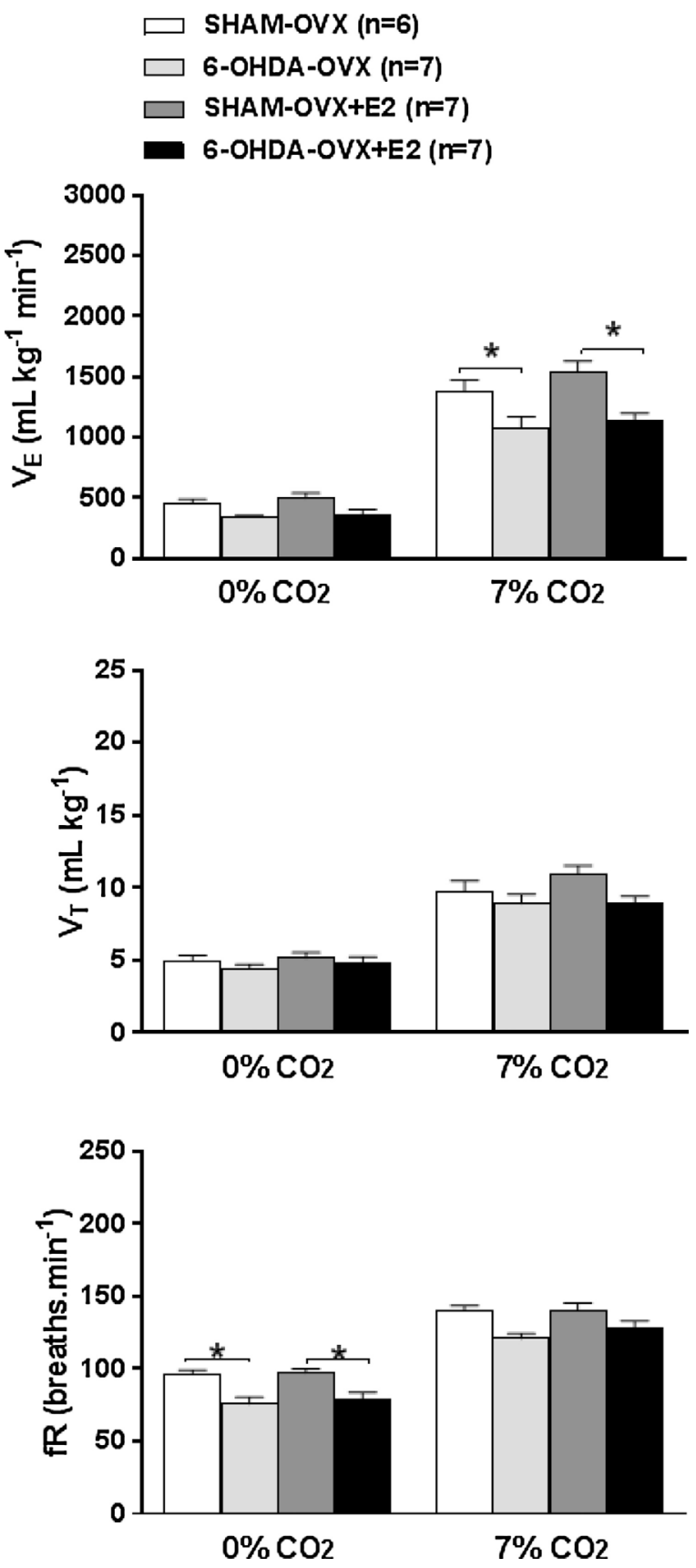

Fig. 6. Ventilation $\left(V_{E}\right)$, tidal volume $\left(V_{T}\right)$ and respiratory frequency ( $f R$ ) in sham (Ascorbic acid) and lesioned (6-OHDA) groups in ovariectomized rats treated with vehicle (OVX) or estradiol (OVX + E2) exposed to normocapnia and hypercapnia $\left(7 \% \mathrm{CO}_{2}\right)$. *Significant differences between sham and lesioned groups.

( $\mathrm{P}<0.0001$; Two-way ANOVA) and $\mathrm{fR}(\mathrm{P}<0.0001$; Two-way ANOVA). Even though the hypercapnic ventilatory response was significantly decreased in 6-OHDA-OVX and 6-OHDA-OVX + E2 groups compared with SHAM groups ( $\mathrm{P}<0.05$; Two-way ANOVA) (Fig. 6), the sensitivity to $\mathrm{CO}_{2}$ was not different among groups (Fig. 7).

Fig. 8A presents the effects of the LC lesion on Tb in OVX and OVX + E2 rats during normocapnia and hypercapnia. Hypercapnia reduced $\mathrm{Tb}$ in all groups $(\mathrm{P}<0.05$; Two-way ANOVA) and neither ablation of $\mathrm{LC}$ neurons nor E2 treatment had any effect on $\mathrm{Tb}$. The fall in $\mathrm{Tb}$ caused by hypercapnia was similar in all groups $(\mathrm{P}<0.0001$; Two-way ANOVA; Fig. 8B).
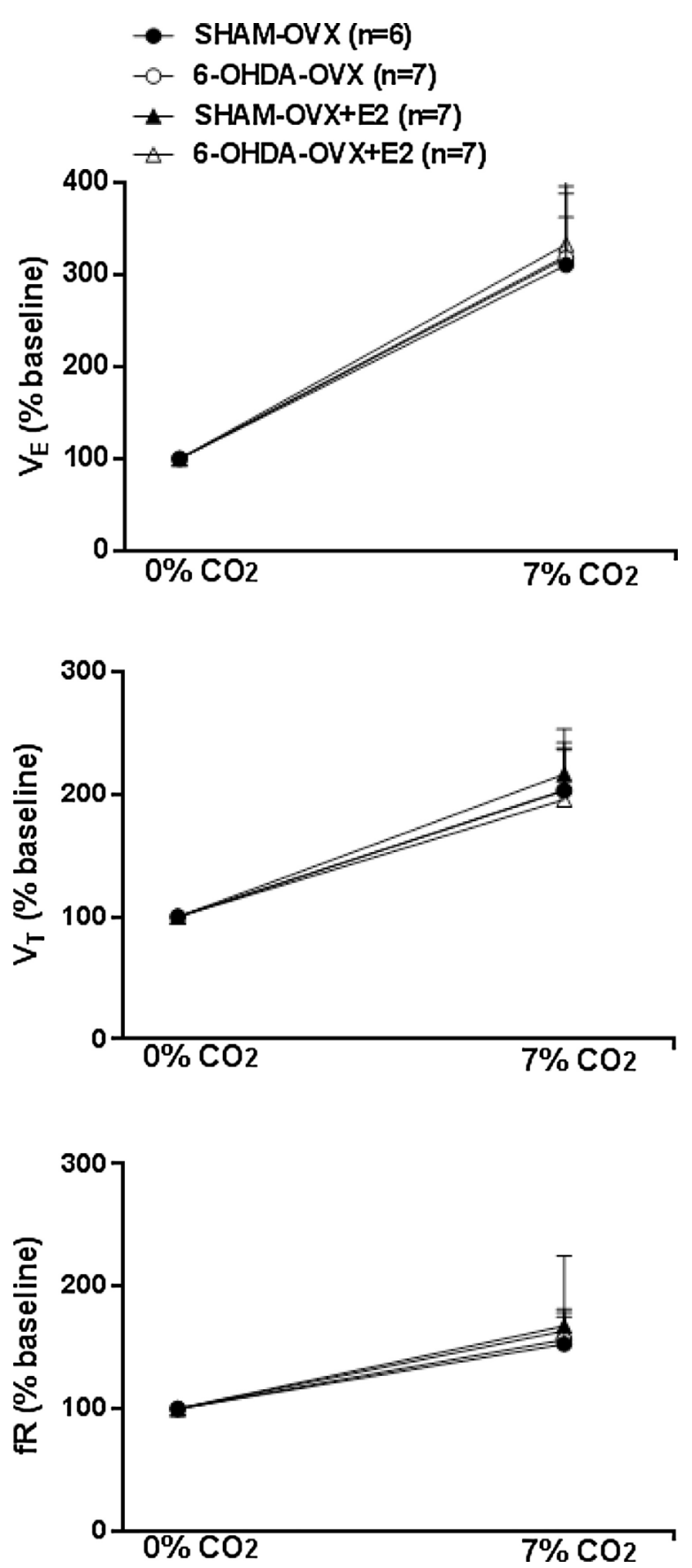

Fig. 7. The relative changes in ventilation $\left(V_{E}\right)$, tidal volume $\left(V_{T}\right)$ and respiratory frequency ( $\mathrm{fR}$ ) in sham (Ascorbic acid) and lesioned (6-OHDA) groups in ovariectomized rats treated with vehicle (OVX) or estradiol (OVX + E2). Data are expressed relative (\%) to levels before $\mathrm{CO}_{2}$ administration as means \pm SEM.

\section{Discussion}

Abnormalities in the LC is related to disorders such as depression, anxiety, panic disorder and Rett syndrome (Alba-Delgado et al., 2013; Taneja et al., 2009). Alba-Delgado et al. (2013) demonstrated marked alterations in morphological, electrical, and neurochemical properties of LC neurons in Rett syndrome model. Moreover, it is known that panic disorder victims are more vulnerable to the effects of $\mathrm{CO}_{2}$ (Bailey et al., 2003) whereas mouse models of Rett syndrome are less $\mathrm{CO}_{2}$ sensitive (Bissonnette et al., 2014; Zhang et al., 2011).

In the current study, LC lesion by 6-OHDA did not affect ventilation under resting conditions, similar to previous studies in males (De Carvalho et al., 2010; Biancardi et al., 2008). However, in OVX females, 
A

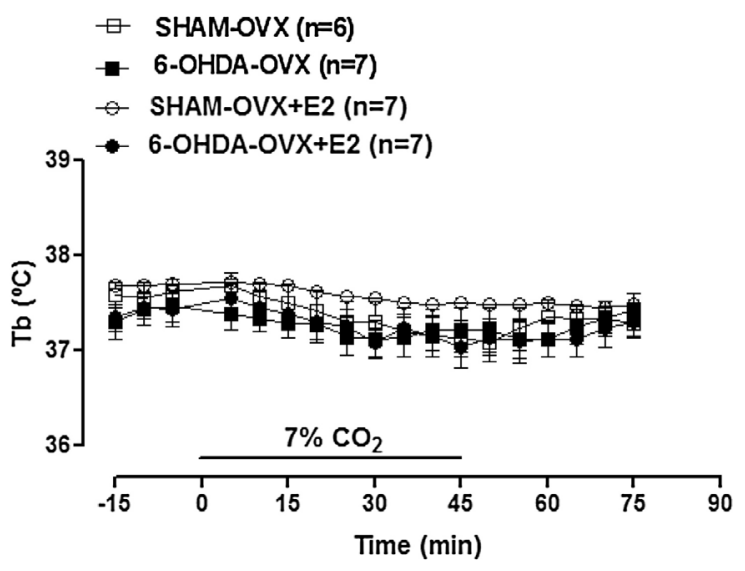

B

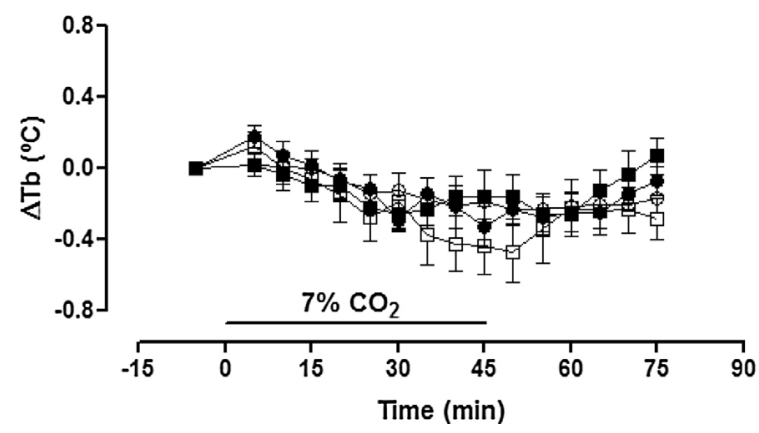

Fig. 8. (A) Body core temperature (Tb) in sham (Ascorbic acid) and lesioned (6-OHDA) groups during normocapnia and hypercapnia $\left(7 \% \mathrm{CO}_{2}\right)$ in females treated with vehicle (OVX) or estradiol (OVX + E2). (B) Variation in body core temperature (Tb) in sham and lesioned animals treated with vehicle or estradiol.

LC lesion caused a decrease in $\mathrm{fR}$ during normocapnia that was not altered by E2 replacement, suggesting that, in the absence of the ovaries, LC noradrenergic neurons provide a tonic excitatory drive to maintain breathing frequency. It is known that ovarian steroids modulate the activity of LC neurons, wherein E2 inhibits LC neuronal activity, while progesterone after E2 pre-treatment stimulates it (Szawka et al., 2009). Since E2 replacement in SHAM group did not affect breathing frequency, it is likely that this hormone is not involved in breathing modulation, at least with the physiological dose used in the present study. Therefore, in the absence of the ovaries, progesterone or even other non-steroidal gonadal hormones, such as anti-Müllerian hormone, activin, inhibin, and follistatin, might act in the LC causing the alteration in respiratory frequency. Nevertheless, further studies are needed to clarify this issue.

Previous studies have indicated a synergistic effect of E2 and progesterone on breathing regulation (Regensteiner et al., 1989); therefore, one could argue that E2 should be replaced together with progesterone to affect ventilation. Unlike E2, progesterone exerts excitatory function in the LC (Szawka et al., 2009) but only after a prior action of E2, since this hormone stimulates synthesis of progesterone receptors in this nucleus (Thornton et al., 1986; MacLusky and McEwen, 1978; Leavitt and Blaha, 1972). Nevertheless, when we performed experiments in females during diestrous (De Carvalho et al., 2016), a phase with relatively stable levels of E2 and progesterone (Smith et al., 1975), no difference in hypercapnia-induced c-Fos expression in the LC was observed. In addition, ventilation in OVX rats under either normocapnia or hypercapnia does not change after administration of progesterone combined with E2 (Marques et al., 2015).

It is known that $\mathrm{LC}$ is an important $\mathrm{CO}_{2}$ chemoreceptor nucleus (De
Carvalho et al., 2016, 2010; Patrone et al., 2014; De Souza Moreno et al., 2010; Biancardi et al., 2008) and brain disorders as depression, anxiety and Rett syndrome (Alba-Delgado et al., 2013; Taneja et al., 2009) are prevalent in women. Thus, we have evaluated the participation of this nucleus in $\mathrm{CO}_{2}$-drive to breath in females and we determined the effects of ovariectomy and E2 in this response. Our data show that non-ovariectomized females with LC lesioned more than $50 \%$ showed a reduction in $\mathrm{CO}_{2}$-drive to breathing. The reduction in $\mathrm{V}_{\mathrm{E}}$ was approximately $20 \%$ due to a decrease in $\mathrm{fR}$. In male rats, the microinjection of 6-OHDA in LC reduced $80 \%$ of noradrenergic neurons and decreased the response to $\mathrm{CO}_{2}$ by approximately $64 \%$ due to a lower $\mathrm{V}_{\mathrm{T}}$ (Biancardi et al., 2008). Studies have shown that female LC has greater volume and dendritic field than male LC (Bangasser et al., 2011; Guillamóm et al., 1988). Thus, LC being lower in males, the neurotoxin could lesion the majority of LC neurons causing a greater attenuation of $\mathrm{CO}_{2}$ response. Moreover, there is the possibility of different mechanisms involved in the response to hypercapnia between males and females implying that LC in females could affect differently the respiratory control in response to $\mathrm{CO}_{2}$ since we observed change in $\mathrm{fR}$ and the same was not showed by Biancardi et al. (2008).

The difference in central $\mathrm{CO}_{2}$ chemosensitivity between males and females has been observed in previous studies. Assessment of the sensitivity of central chemoreceptors to $\mathrm{CO}_{2}$ in vivo indicates that the $\mathrm{CO}_{2}$ threshold for the activation of retrotrapezoid neurons (RTN) neurons is higher in female than in male adult mice (Niblock et al., 2012; Niblock et al., 2010). Niblock et al. (2012) have observed that female RTN neurons are activated after $10 \% \mathrm{CO}_{2}$ exposure, but not to $5 \% \mathrm{CO}_{2}$ in vivo. On the other hand, male RTN neurons are activated both when exposed to 5 and $10 \% \mathrm{CO}_{2}$, indicating that there are gender differences in the $\mathrm{CO}_{2}$ threshold required for the activation of the RTN neurons, in which males seem to be more sensitive (Niblock et al., 2012; Niblock et al., 2010).

The SHAM-NOVX animals presented an increase of $250 \%$ of the hypercapnic ventilatory response (Fig. 4), whereas in SHAM-OVX groups, the increase of ventilation was approximately $200 \%$ in both groups (Fig. 7). Similarly, we found that ovariectomy promoted an attenuation $(43 \%)$ of the hypercapnic hyperventilation, compared with the response obtained from intact females (Marques et al., 2015). Further, hormonal replacement with E2 did not restore the effects of ovariectomy on $\mathrm{CO}_{2}$ chemosensitivity. Interestingly, when OVX and OVX + E2 females were lesioned with 6-OHDA, the ventilatory response to $\mathrm{CO}_{2}$ was similar compared to sham groups. Since $\mathrm{CO}_{2}$ chemosensitivity is already decreased in OVX animals, LC lesion did not promote further reduction of $\mathrm{CO}_{2}$ ventilatory response. As suggested before, since $\mathrm{E} 2$ treatment in SHAM animals did not affect the ventilatory response to $\mathrm{CO}_{2}$, similar to our previous data (Marques et al., 2015), it is possible that this hormone is not involved in respiratory regulation during hypercapnic challenge. Therefore, other ovarian hormones might be involved in this regulation.

Regarding LC participation in thermoregulation, there is evidence that catecholaminergic LC neurons are part of a thermoeffector neuronal pathway that is specifically activated by pyrogens (e.g. $\mathrm{PGE}_{2}$ ) to induce thermogenesis and produce fever in a subthermoneutral environment (Almeida et al., 2004). The present study was performed in thermoneutral condition and LC noradrenergic neurons lesion did not change $\mathrm{Tb}$ corroborating previous studies performed in males (De Carvalho et al., 2010; Biancardi et al., 2008). Therefore, LC seems to participate in some way involved in thermoregulation but only in subthermoneutral condition and not in thermoneutral condition.

Hypercapnia reduced $\mathrm{Tb}$ in all groups corroborating our previous study in which exposure to $7 \% \mathrm{CO}_{2}$ caused a drop in $\mathrm{Tb}$ in OVX and cycling female rats (Marques et al., 2015). Thus, the reduction in temperature during hypercapnia in females may not be caused by hormone fluctuations since both OVX and regularly cycling females present this alteration.

In conclusion, our data show that LC noradrenergic neurons in 
intact females exert an excitatory modulation in the hypercapnic ventilatory response that is not observed in OVX females. In addition, LC noradrenergic neurons of OVX females seems to provide a tonic excitatory drive to maintain breathing frequency, and this response that is not functionally influenced by E2.

\section{Acknowledgments}

This work was supported by the Fundação de Amparo à Pesquisa do Estado de São Paulo (FAPESP) and the Conselho Nacional de Desenvolvimento Científico e Tecnológico (CNPq). Débora de Carvalho was the recipient of a FAPESP PhD scholarship (2008/57748-9).

\section{References}

Alba-Delgado, C., Llorca-Torralba, M., Horrillo, I., Ortega, J.E., Mico, J.A., SánchezBlázquez, P., Meana, J.J., Berrocoso, E., 2013. Chronic pain leads to concomitant noradrenergic impairment and mood disorders. Biol. Psychiatry 73 (1), 54-62.

Almeida, M.C., Steiner, A.A., Coimbra, N.C., Branco, L.G.S., 2004. Thermoeffector neuronal pathways in fever: role of the locus coeruleus. J. Physiol. 558 (1), 283-294.

Andrade, L.H.S.G., Viana, M.C., Silveira, C.M., 2006. Epidemiologia dos transtornos psiquiátricos na mulher. Rev. Psiq. Clín. 33 (2), 43-54.

Aston-Jones, G., Foote, S.L., Segal, M., 1985. Impulse conduction properties of noradrenergic locus coeruleus axons projecting to monkey cerebrocortex. Neuroscience $15,765-777$

Bailey, J.E., Argyropoulos, S.V., Lightman, S.L., Nutt, D.J., 2003. Does the brain noradrenaline network mediate the effects of the $\mathrm{CO} 2$ challenge? J. Psychopharmacol. 17 (3), 252-259.

Bangasser, D.A., Zhang, X., Garachh, V., Hanhauser, E., Valentino, R.J., 2011. Sexual dimorphism in locus coeruleus dendritic morphology: a structural basis for sex differences in emotional arousal. Physiol. Behav. 103, 342-351.

Bartlett, D.J.R., Tenney, S.M., 1970. Control of breathing in experimental anemia. Respir. Physiol. 10, 384-395.

Biancardi, V., Bicego, K.C., Almeida, M.C., Gargaglioni, L.H., 2008. Locus coeruleus noradrenergic neurones and CO2 drive to breathing. Eur. J. Physiol. 455, 1119-1128.

Bissonnette, J.M., Schaevitz, L.R., Knopp, S.J., Zhou, Z., 2014. Respiratory phenotypes are distinctly affected in mice with common Rett syndrome mutations MeCP2 T158A and R168X. Neuroscience 267, 166-176.

Coates, E.L., Li, A., Nattie, E.E., 1993. Widespread sites of brainstem ventilatory chemoreceptors. J. Appl. Physiol. 75, 5-14.

Dahlström, A., Fuxe, K., 1964. Evidence for the existence of monoamine-containing neurons in the central nervous system. I. Demonstration of monoamine in the cell bodies of brain-stem neurons. Acta Physiol. Scand. 62 (232), 1-55.

De Blas, M.R., Segovia, S., Guillamón, A., 1990. Effect of postpuberal gonadectomy on cell population of the locus coeruleus in the rat. Med. Sci. Res. 18, 355-356.

De Carvalho, D., Bícego, K.C., Castro, O.W., Silva, G.S.F., Garcia-Cairasco, N., Gargaglioni, L.H., 2010. Role of neurokinin-1 expressing neurons in the locus coeruleus on ventilatory and cardiovascular responses to hypercapnia. Respir. Physiol. Neurobiol. 172, 24-31.

De Carvalho, D., Marques, D.A., Bernuci, M.P., Leite, C.M., Araújo-Lopes, R., AnselmoFranci, J., Bícego, K.C., Szawka, R.E., Gargaglioni, L.H., 2016. Role of sex hormones in hypercapnia-induced activation of the locus coeruleus in female and male rats. Neuroscience 313, 36-45.

De Souza Moreno, V., Bícego, K.C., Szawka, R.E., Anselmo-Franci, J.A., Gargaglioni, L.H., 2010. Serotonergic mechanisms on breathing modulation in the rat locus coeruleus. Pflugers Arch. 459 (3), 357-368.

Filosa, J.A., Dean, J.B., Putnam, R.W., 2002. Role of intracellular and extracellular pH in the chemosensitive response of rat locus coeruleus neurones. J. Physiol. 541, 493-509.

Guillamóm, A., De Blas, M.R., Segovia, S., 1988. Effects of sex steroids on the development of the locus coeruleus in the rat. Dev. Brain Res. 40, 306-310.

Hobson, J.A., McCarley, R.W., Wyzinski, P.W., 1975. Sleep cycle oscillation: reciprocal discharge by two brainstem neuronal groups. Science $189,55-58$.

Leavitt, W.W., Blaha, G.C., 1972. An estrogen-stimulated, progesterone-binding system in the hamster uterus and vagina. Steroids 19, 263-274.

MacLusky, N.J., McEwen, B.S., 1978. Oestrogen modulates progestin receptor concentrations in some rat brain regions but not in others. Nature 274 (5668), 276-278.
Marques, D.A., de Carvalho, D., da Silva, G.S., Szawka, R.E., Anselmo-Franci, J.A., Bícego, K.C., Gargaglioni, L.H., 2015. Ventilatory, metabolic, and thermal responses to hypercapnia in female rats: effects of estrous cycle, ovariectomy, and hormonal replacement. J. Appl. Physiol. 119 (1), 61-68.

Moore, R.Y., Bloom, F.E., 1979. Central catecholamine neuro systems: anatomy and physiology of the norepinephrine and epinephrine systems. Ann. Rev. Neurosci. 2, 113-168.

Niblock, M.M., Gao, H., Li, A., Jeffress, E.C., Murphy, M., Nattie, E.E., 2010. Fos-Tau-LacZ mice reveal sex differences in brainstem c-fos activation in response to mild carbon dioxide exposure. Brain Res. 1311, 51-63.

Niblock, M.M., Lohr, K.M., Nixon, M., Barnes, C., Schaudies, M., Murphy, M., 2012. Cells in the female retrotrapezoid region upregulate c-fos in response to $10 \%$, but not $5 \%$, carbon dioxide. Brain Res. 1433, 62-68.

Oyamada, Y, Ballantyne, D., Muckenhoff, K., Scheid, P., 1998. Respiration-modulated membrane potential and chemosensitivity of locus coeruleus neurones in the in vitro brainstem-spinal cord of the neonatal rat. J. Physiol. 513, 381-398.

Patrone, L.G., Bícego, K.C., Hartzler, L.K., Putnam, R.W., Gargaglioni, L.H., 2014. Cardiorespiratory effects of gap junction blockade in the Locus coeruleus in unanesthetized adult rats. Respir. Physiol. Neurobiol. 190, 86-95.

Paxinos, G., Watson, C., 1998. The Rat Brain in Stereotaxic Coordinates, $3^{\mathrm{a}}$ ed. Academic, San Diego, CA.

Pendergast, J.S., Tuesta, L.M., Bethea, J.R., 2008. Oestrogen receptor beta contributes to the transient sex difference in tyrosine hydroxylase expression in the mouse locus coeruleus. J. Neuroendocrinol. 20, 1155-1164.

Pineda, J., Aghajanian, G.K., 1997. Carbon dioxide regulates the tonic activity of locus ceruleus neurons by modulating a proton- and polyamine-sensitive inward rectifier potassium current. Neuroscience 77, 723-743.

Putnam, R.W., Filosa, J.A., Ritucci, N.A., 2004. Cellular mechanisms involved in $\mathrm{CO}_{2}$ and acid signaling in chemosensitive neurons. Am. J. Physiol. Cell Physiol. 287 (6), 1493-1526.

Rapkin, A.J., Mikacich, J.A., Moatakef-Imani, B., Rasgon, N., 2002. The clinical nature and formal diagnosis of premenstrual, postpartum, and perimenopausal affective disorders. Curr. Psychiatry Rep. 4 (6), 419-428.

Regensteiner, J.G., Woodard, W.D., Hagerman, D.D., Weil, J.V., Pickett, C.K., Bender, P.R., Moore, L.G., 1989. Combined effects of female hormones and metabolic rate on ventilatory drives in women. J. Appl. Physiol. 966 (2), 808-813.

Segovia, S., Guillamón, A., De Blas, M.R., 1990. Aged-related changes in cell population in locus coeruleus in the rat. Med. Sci. Res. 18, 29-30.

Serova, L., Rivkin, M., Nakashima, A., Sabban, E.L., 2002. Estradiol stimulates gene expression of norepinephrine biosynthetic enzymes in rat Locus coeruleus. Neuroendocrinology 75, 193-200.

Silva, C.A., Vicente, M.C., Tenorio-Lopes, L., Soliz, J., Gargaglioni, L.H., 2017. Erythropoietin in the Locus coeruleus attenuates the ventilatory response to $\mathrm{CO}_{2}$ in rats. Respir. Physiol. Neurobiol. 236, 11-18.

Singewald, N., Philippu, A., 1998. Release of neurotransmitters in the Locus coeruleus. Prog. Neurobiol. 56, 237-267.

Smith, M.S., Freeman, M.E., Neill, J.D., 1975. The control of progesterone secretion during the estrous cycle and early pseudopregnancy in the rat: prolactin, gonadotropin and steroid levels associated with rescue of the corpus luteum of pseudopregnancy. Endocrinology 96 (1), 219-226.

Szawka, R.E., Rodovalho, G.V., Monteiro, P.M., Carrer, H.F., Anselmo-Franci, J.A., 2009. Ovarian-steroid modulation of Locus coeruleus activity in female rats: involvement in luteinising hormone regulation. J. Neuroendocrinol. 21, 629-639.

Taneja, P., Ogier, M., Brooks-Harris, G., Schmid, D.A., Katz, D.M., Nelson, S.B., 2009. Pathophysiology of locus ceruleus neurons in a mouse model of Rett syndrome. J. Neurosci. 29 (39), 12187-12195.

Taxini, C.L., Puga, C.C., Dias, M.B., Bícego, K.C., Gargaglioni, L.H., 2013. Ionotropic but not metabotropic glutamatergic receptors in the Locus coeruleus modulate the hypercapnic ventilatory response in unanaesthetized rats. Acta Physiol. (Oxf) 208 (1), $125-135$.

Thornton, J.E., Nock, B., McEwen, B.S., Feder, H.H., 1986. Estrogen induction of progestin receptors in microdissected hypothalamic and limbic nuclei of female guinea pigs. Neuroendocrinology 43 (2), 182-188.

Xu, S., Guo, S., Jiang, X., Yin, Q., Umezawa, T., Hisamitsu, T., 2003. Effect of indomethacin on the c-fos expression in AVP and TH neurons in rat brain induced by lipopolysaccharide. Brain Res. 966, 13-18.

Zhang, X., Su, J., Cui, N., Gai, H., Wu, Z., Jiang, 2011. The disruption of central $\mathrm{CO}_{2}$ chemosensitivity in a mouse model of Rett syndrome. Am. J. Physiol. Cell Physiol. 301 (3), C729-38. 